Working with mediagrams: a methodology for collaborative research on mediational repertoires in multilingual families

Lexander, Kristin Vold ${ }^{\mathrm{a} *}$ and Androutsopoulos, Jannis ${ }^{\mathrm{b}}$

${ }^{a}$ MultiLing Center for Multilingualism in society across the lifespan, University of Oslo, Norway; ${ }^{b}$ MultiLing University of Oslo, Norway/Institut für Germanistik, Universität Hamburg, Germany

*Postboks 1102, Blindern, 0317 Oslo, Norway, k.v.lexander@iln.uio.no 


\title{
Working with mediagrams: a methodology for collaborative research on mediational repertoires in multilingual families
}

\begin{abstract}
The aim of this paper is to contribute to the current discussion of methodology in sociolinguistics with regards to the rapidly changing landscape of mediated communication (Androutsopoulos and Stæhr 2018) through the presentation and evaluation of mediagrams as a methodology for research on transnational interaction. Based on a study of communication in families with Senegalese background living in Norway, we develop a visualization scheme for the analysis of mediational repertoires in the form of graphs for data collection, presentation and analysis.
\end{abstract}

Starting with a review of other relevant visualizations used in research on language practices and an introduction to the context of our study, we present the collaborative mediagram research process: After participants' map drawing, data selection and sharing, the data is coded to be visualized in mediagrams showing the individual participants' network of interlocutors, tools, modalities (spoken/written) and languages used for communication. This visualization is used in follow-up interviews leading up to modifications of the mediagrams that at the next stage are used in the analysis of the participants' mediational repertoires. In the final part of the paper, we discuss blind-spots and possibilities of application in other studies and evaluate mediagram research in view of citizen sociolinguistics (Svendsen 2018).

Keywords: multilingual families; digital communication; methodology; collaborative research; mediagrams; visualization

Word count: 6997

\section{Introduction}

This paper presents a method for the elicitation, visualization and analysis of the interplay between language and media choices in transnational digital communication. Research across disciplines shows that digital media create new opportunities for 
transnational interpersonal communication. In media studies, Madianou (2014) suggests that the possibilities of transnational connectivity afforded by digital communication transform the entire experience of migration. Sociolinguistics and multilingualism research discuss digital media as a space where people can creatively draw on existing semiotic resources as much as acquire new ones (Creese and Blackledge 2018; Jorgensen et al. 2011; Lee 2017), and the interplay of transnational mobility and digital communication has been theorised as a driving force behind superdiversity (Androutsopoulos and Juffermans 2014; Blommaert and Rampton 2011). Research on multilingual families, too, is increasingly interested in how contexts of "social media and technology saturation” (King and Lanza 2017, 2) may affect family language practices. Parents may facilitate their children's digital interaction in certain languages with specific interlocutors, and parent's influence on such involvement is considered crucial for children's heritage language development (Curdt-Christiansen and Lanza 2018). Digital communication also seems to play a role in counteracting language shift as it enables people to create spaces for heritage language practice and informal learning (Lanza and Lexander, forthc; Reershemius 2017). At the same time, the choice of a media channel can in itself be meaningful to participants in mediated family communication and consequential for the interaction carried out (Madianou and Miller 2012).

In this paper we address what we identify as a gap in this scholarship on multilingual speakers, transnational communication and digital media. This gap concerns the relation of language choice to the wide range of digital media that are available for transnational communication. While most research has examined language use online in a single media channel, the findings of our ethnographic fieldwork suggest that migrants and their families draw on a number of digital channels for transnational 
communication, also reflecting about the adequacy of channel choice to specific interlocutors.

Consider for instance the following observation, which was collected in the project this paper reports on. The main character here is a Senegalese-background female adolescent, whom we call Rama. In the course of a day, Rama uses several parts of her linguistic repertoire and several media channels to communicate with family and friends in Norway and elsewhere in the world. During a phone call to her grandmother in Senegal, which is conducted in spoken Joola, Rama receives a Snapchat video, in spoken Norwegian, from her friends from school. Then she receives a voice message in Wolof from her cousin in France and a good-night message from her mother who lives in Senegal, written in French and English.

Practices of this kind, which rely on the interplay of various languages and media for interpersonal communication, are quite common in the families researched in this project. To theorise them we pull together the notions of linguistic repertoire (Androutsopoulos 2014; Blommaert and Backus 2013; Busch 2015) and mediational means (Scollon 2001) to coin the notion of a 'mediational repertoire'. A mediational repertoire can be thought of as a socially and individually structured configuration of semiotic and technological resources. Depending on the affordances (Bucher and Helmond 2016) of a given software application (e.g. WhatsApp or Telegram), a mediational repertoire comprises various modalities of language (speaking, writing, or signing), and various sets of pictographic and multimedia signs (e.g. emoji, memes, animated gifs, video clips). In the case of Rama, her repertoire comprises the languages she speaks and writes to her distant interlocutors, with the choice between speaking and writing depending on the choice of software app. 
The aim of this paper is to outline a method for the elicitation and visualization of such mediational repertoires. We call this method 'mediagram', a term coined by the second author in analogy to the familiar term, sociogram (see section 4 for discussion). A mediagram is a way of visualising a speaker's communicative choices at the level of language, linguistic modality, and media channel. Attempts to develop such visualizations are scarce, but in our view urgently pressing. This paper therefore responds to a methodological challenge in the study of multilingual communication in a digital era (Androutsopoulos and Stæhr 2018).

We begin with a brief review of two sociolinguistic techniques for visualizing linguistic repertoires, notably the language portrait method and transnational communication network graphs (section 2). After a brief introduction to our study of multilingual families of Senegalese background in Norway (section 3) we introduce mediagrams and explain their graphical make-up (section 4). We discuss the collaborative process of compiling and using a mediagram through various stages of the research process (section 5), then illustrate how mediagrams can be used to analyse language and media choices (section 6). In concluding, we discuss the method's potential for further development, its contribution to citizen sociolinguistics and its present limitations, thereby emphasising its contextualization in a broader approach to blended ethnography (Androutsopoulos and Stæhr 2018; Varis 2016).

\section{Language portraits and communication networks: visualizing linguistic repertoires}

Sociolinguistic research on computer-mediated communication has investigated a wide range of multilingual practices online (see Lee 2017 for an overview). The overwhelming majority of this research is based on data from one specific channel, platform or communication mode, and linguistic choices of the same user(s) across 
various communication modes are hardly ever examined. This holds true for the rare visualization of multilingual data from online social networks. For example, Paolillo $(1999,2001)$ visualizes the distribution of five sociolinguistic variables, including the use of Hindi, in an Internet Relay Chat channel by the name of \#india. His network analysis shows Hindi is preferred by the most central and powerful group in this channel, which has the strongest in-group ties, whereas other, more peripheral user subgroups score low for Hindi. In another study, Androutsopoulos (2015) examines the choice of German, Greek and English in Facebook discussions among seven Greekbackground classmates in Germany. The relation of language choice and interpersonal addressivity is visualized in a social network graph, which shows that bilingual exchanges are quite specific to a pair of female 'best friends'. Both studies use only data from one specific channel and offer no information on linguistic practices of the same users in other media channels.

We briefly review two techniques for the visualization of multilingual repertoires we found useful in developing the mediagram method. The first, language portraits, is part of an ethnographically grounded, language-biographical approach to multilingualism pioneered by Brigitta Busch (Busch 2012, 2013, 2017; Purkharthofer 2017, Wilson 2019). Busch's understanding of a linguistic repertoire focuses on how speakers associate certain linguistic resources with particular socio-biographical experiences and communicative spaces. As people's habitual linguistic choices are not necessarily conscious (Busch 2017), bringing them to the fore is a methodological and analytical challenge. Language portraits are a technique developed to this aim. The speakers are provided with a body silhouette and multicolored pens and are asked to map the codes and languages that mean something in their lives. This yields two sets of data, i.e. the visualization itself and a narrative that is "elicited by the image" (Busch 
2012, 518). Busch argues this narrative enables speakers to articulate their

Spracherleben or experience of language, i.e. "what meaning speakers attach to their linguistic resources, their language practices, and their language attitudes in particular, and what significant lived experiences underpin these constructs of meaning" (Busch 2012, 518-519). As discussed below (section 5), we used language portraits in our initial interviews with family members to introduce questions of language use and to prelude the joint drawing of media maps, which provide the raw material for mediagrams.

Two recent attempts to visualize the interplay of language and media choices in individual communication networks are Brandehof (2014) and Nemcová (2016). Both are couched in language and superdiversity research and aim "to unravel the social structure of superdiverse diaspora networks through analyzing sociolinguistic repertoires" (Brandehof 2014, 28). Brandehof's study of Cameroonian migrants in Belgium draws on interviews and ethnographic observation to visualize linguistic and media choices towards various interlocutors and to various purposes. The graph in Figure 1 shows the communication network of one person, Amadou. His interlocutors are represented in terms of kinship and social relationships (e.g. "daughter", "Belgians") and arranged by geographical location (Cameroon, Gent). Each interlocutor is connected to two nodes, one for media choices (e.g. "text messages", “calls") and one for languages (e.g. "Pidgin", "Dutch"). The graph includes language and media choices tied to certain purposes rather than interlocutors (e.g. "Searching for jobs"). Colourcoding is used to distinguish interlocutors, locations and languages. Nemcová (2016), too, draws on interview data visualize the personal networks of three students with different geographical and migrant background who study in the Netherlands and in China. In the example given in Figure 2, the informant's interlocutors are grouped 
together by geographical location (Netherlands, Russia), in part subdivided by region or city (Eindhoven, Tilburg). Icons are used to represent languages and media applications. Domains of communication are placed in boxes and frequency of contact is indicated by color-coding. ${ }^{\text {i }}$

Figure 1 Communication network of Amadou (Brandenhof 2014, 35)

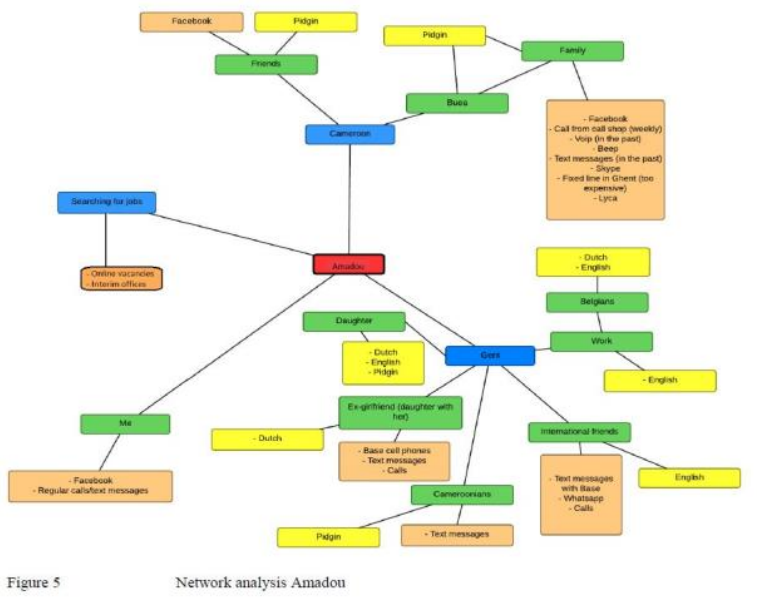

Figure 2 Visual representation of Nadya's network (Nemcová 2016, 20)

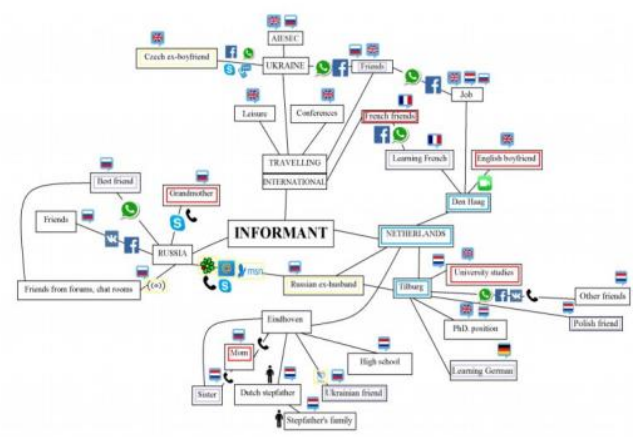

Both language portraits and multilingual network graphs offered inspiration to the method presented in this paper. Mediagrams resemble language portraits and communication graphs in that they are ego-centred, i.e. visualize one individual's language choices to relevant partners rather than representing the distribution of 
linguistic features across an entire social network. Mediagrams differ to language portraits not only in the obvious sense of including distinct modalities of language and media choices, but also by representing meditational choices directed to specific interlocutors. Mediagrams differ to multilingual network graphs in that they are based on samples of digital interaction, too, besides interview data and ethnographic observation. More details are discussed in section 4 below.

\section{Research context: Senegalese families in Norway}

The method presented in this paper is developed in an ethnographic project on multilingualism and mediated communication in Norwegian families with Senegalese background. The project's main aim is to understand relations between the family members' multilingual repertoires, their digital interaction partners, and the media they use to communicate with them. Specific questions include the implications of mediated communication for the use of heritage languages and practices of mode switching, i.e. the alternation between writing and speaking in media such as WhatsApp. Our scope is thus broader than much research on family multilingualism (e.g. Curdt-Christiansen and Lanza 2018; Fogle and King 2013). The visualization method presented in this paper is one way of establishing a connection from single interactional episodes to the broader context of digitally mediated communication in the family, thereby taking into consideration different generations, different geographical locations of interlocutors, and different communication strategies. We examine language use by family members to interlocutors from the nuclear family, relatives and close friends, in Senegal and elsewhere, thereby paying close attention to the diverse language experiences of individual speakers, given that "bilingualism and multilingualism mean different things to different generations and to different individuals within the same family" (Zhu and Li 2016, 656). 
Four families were recruited to the study. As the aim is to look at language use in different types of relationship within transnational families, in families with diverse linguistic repertoires, the families differ with regards to background and composition. ${ }^{\text {ii }}$

- Family 1: two parents born in Senegal, a son (16 years old) born in Senegal, a daughter (10 y.o.) and a son (6 y.o.) born in Norway

- Family 2: mother born in Norway, father born in Senegal, two children (5 and 8 y.o.) born in Norway

- In Family 3: a father and a daughter (14 y.o.), both born in Senegal

- Family 4: a mother with four children, two born in Senegal (20 and 19 y.o.) and two born in Norway (16 and 10 y.o.)

We followed the families over two years, collecting three different sets of data. Since these are implicated in the development of the mediagram method described below, they are only introduced here in brief. The first data set consists of ethnographic interviews, some with individual participants, others among two or more family members. These interviews involve various means of visual support, including language portraits, media maps (discussed below) and media diaries. The second data set comprises excerpts from the interviewee's digital interactions, such as text and voice messages, message threads, photos and videos. These are collected through downloads, screenshots or photos and are discussed in the interviews. Field notes from the observation of natural communication in the family home make up the third data set. These data form the backdrop for ethnographic triangulation in the sense of digital ethnography (Androutsopoulos 2008; Varis 2016). As the following discussion illustrates, mediagrams are contextualized within this procedure. Their compilation relies on interview reports as well as digital data participants decide to share with us 
(section 5). Once a mediagram is composed, it may be used in follow-up interviews for verification and to elicit more data (section 6).

\section{Introducing mediagrams}

Mediagrams are visual representations of patterns of language, modality, and media choices in family communication. The idea, and the term itself, are inspired by sociograms, a key method for the visualization of social network data (see e.g. Hoang et al. 2006), which has been widely received in sociolinguistics and adapted for the study of linguistic variation and change (Milroy 1980; Sharma 2017). The design of mediagrams orients to sociograms for ego networks (or personal networks), which represent social relationships between a core informant (ego) and relevant partners (alters). We adopt the circular layout and the 'ego star' graphic pattern that is common in sociograms in sociolinguistics scholarship (Sharma 2017). Differences of mediagram design from other sociolinguistic applications of the technique concern the kind of represented information and the graphic modalities deployed to this aim. Shapes, layout, and colour are deployed to represent different languages, language modalities, and mediational tools (i.e. software apps), the making of the graphs thereby relying on subjective (interview reports) as well as objective data (excerpts of digital interaction participants shared with us). Similar to the use of sociograms in social-scientific research, mediagrams are a graphical representation of qualitative data aimed at making patterns visible and at presenting information during the data-gathering process (Drahota and Dewey 2008; Hogan et al. 2007; Tubaro et al. 2014).

Figure 3 shows the mediagram of one participant, the daughter of family 3 (D3). It depicts her language, modality and media choices for interaction with nuclear family members, close friends in Norway (both to the right), and extended family members in Senegal and elsewhere, in this case France. 
Figure 3 Mediagram of the daughter in family 3 (D3)

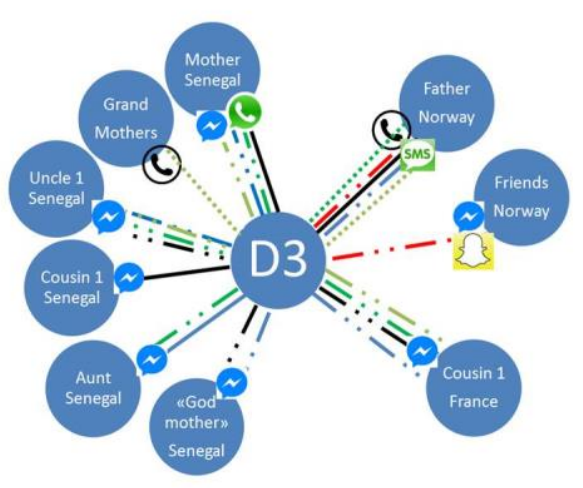

Mediagrams use colours to distinguish languages and line style to represent language modality. This graph features Norwegian (red), Wolof (green), Joola (light green), French (blue), and English (black). A continuous line indicates written, a dotted line spoken language use, and a mixed-type line is for the use of both modalities. In such cases a participant reports that communication with a certain distant interlocutor involves both speaking (e.g. phone calls, voice messages) and writing (text messaging). For example, D3 reports that she communicates with her mother in Joola, Wolof and French, both in written and spoken mode, as well as in English for text messaging. In some cases, modality and language choice are more restricted for a given pair of interlocutors. D3 communicates with her grandmothers in Senegal only via phone calls in spoken Joola. Media channel choices for each interlocutor are represented with distinctive icons next to each interlocutor circle. D3 uses Facebook messenger to most of her interlocutors, WhatsApp to her mother in Senegal, and Snapchat (yellow square with white symbol) to her closest friends in Norway who are also part of the graph.

The visual structure of mediagrams differs in several respects to the network graphs by Brandehof (2014) and Nemcová (2016). Mediagrams do not represent communication purposes such as travelling or searching for jobs, but focus on language and media choices for interaction with specific interlocutors. Mediagrams encode modality of language, an aspect we found analytically and theoretically important. ${ }^{\text {iii }}$ 
However, mediagrams differ from Nemcová's graphs in that they do not encode frequency of contact between interlocutors, an issue we take up in the concluding discussion (section 7).

\section{Creating mediagrams: a collaborative process}

The creative process that leads up to a mediagram is a collaborative endeavour that starts at the first meeting with participants and continues throughout the data collection phase. We outline this process here and discuss its relation to citizen sociolinguistics later (cf. section 7).

In the first interview, the participants draw language portraits to talk about their linguistic repertoires. One such portrait is by the oldest son in family 1 (Figure 4).

Figure 4 Language portrait made by the oldest son in family 1 (S1.1)

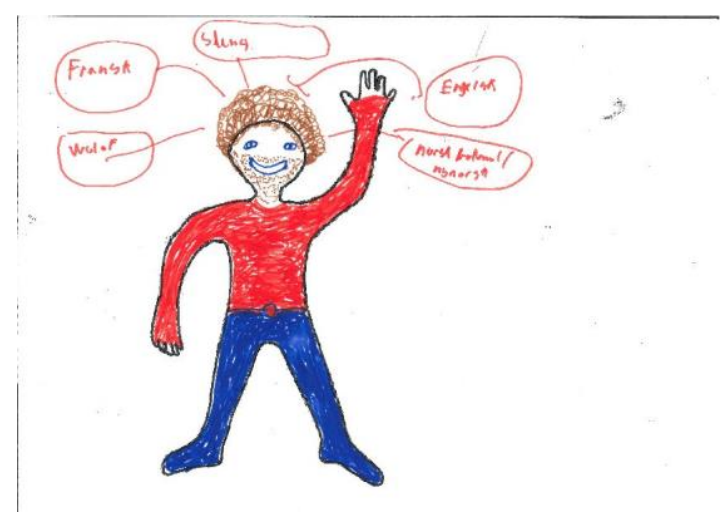

The portrait presents a young man with lines going from the head to bubbles with various language labels: Wolof, Fransk (French), Sleng (slang), Engelsk (English), Norsk bokmål/nynorsk (Norwegian Bokmål and New Norwegian, Norway’s two official written languages, both taught in high school). Commenting on the drawing, S.1.1 says, "I have drawn a guy who is a little confused, because he has kind of, he is supposed to know so many languages, so he may mix" (translated from Norwegian). He says he knows all of these languages and needs to learn more, but that it is difficult because there is så my språk, 'so much language', in his mind. He says he uses Norwegian and 
'slang' with friends, and Norwegian as well as English and French in school. He also links French to relatives in Senegal and Gabon with whom he uses this language on WhatsApp and Viber. Hence it is S1.1 himself who shifts attention to digital communication, indicating its importance for his language choices.

Following the portrait-drawing activity, participants are invited to visualize their mediated communication by starting from a circle that represents themselves. They can then draw lines to relevant interlocutors, use colours to represent languages, and write their media choices right into the drawing. Figure 5 shows a media map drawn by the father in family 2, and Figure 6 shows the mediagram we eventually compiled for this participant.

Figure 5 Hand-drawn media map by the father in family 2 (F2) 


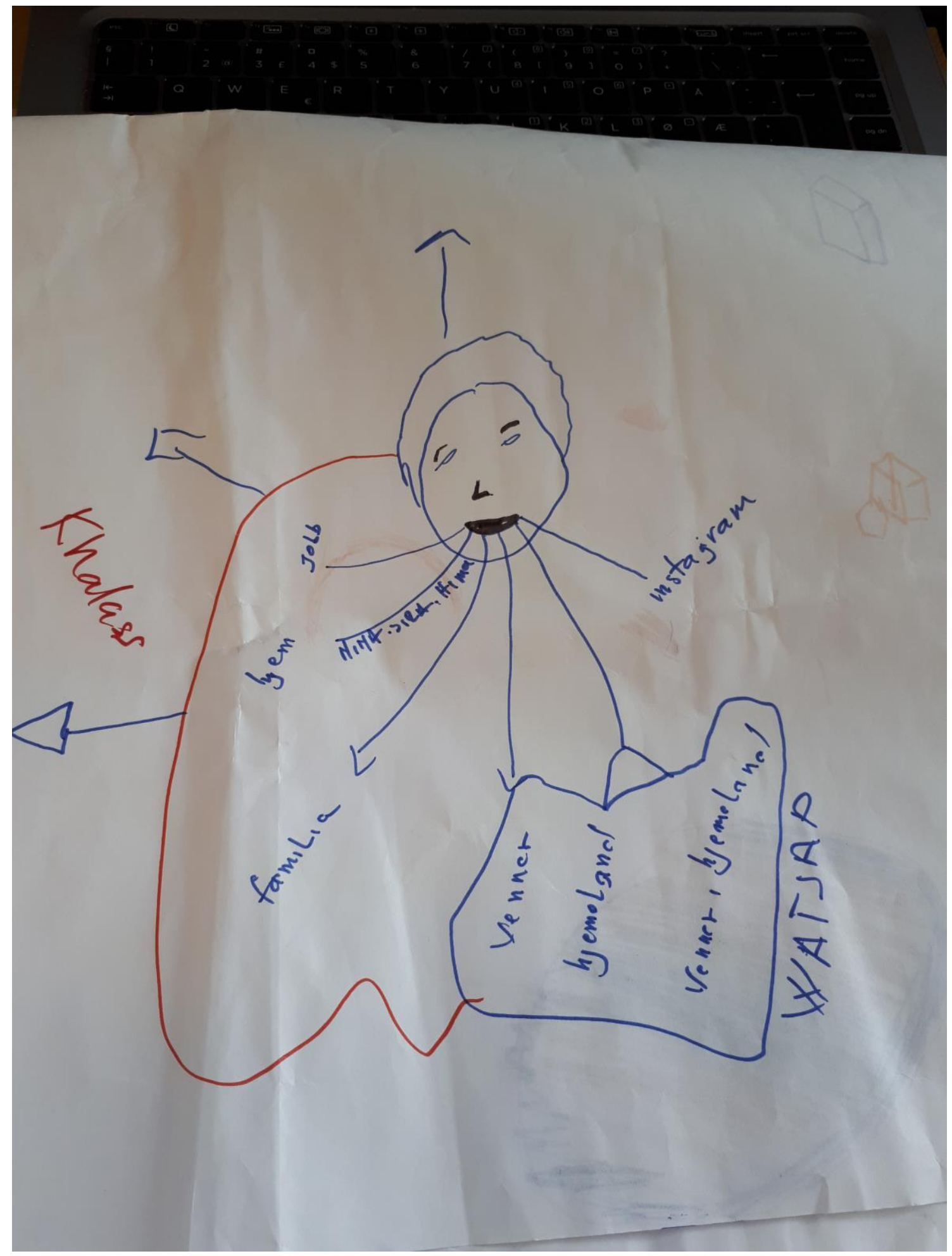

The participants are free to draw their media map as they like. Some draw themselves, others prefer to let the researcher make the drawing while providing information they want to see included. In this case, F2 presents his mediated 
communication as coming out of his mouth and his head. He draws a red line to encapsulate his interlocutors and activities to the left of the head. Closest to his mouth, the names of his wife and two children are lined-up along a vector that emanates from the mouth. A bit further to the left come more vectors with the items job ('work'), hjem ('home'), the latter on the same vector with family members, and familia - we don't know why he chose this variant of the word. To the left of the red line, delimited from the family space, is the Wolof name of a radio show, Khalass, written down by the researcher to represent information provided by F2 in the course of the drawing. To the right, three more vectors connect the figure's mouth to certain social spaces and media apps. The items venner ('friends') and hjemland ('homeland') are framed with a blue line, followed to the right by the word WhatsApp (in capitals), while Instagram stands somewhat separated.

Hand-made media maps of this kind provide a focal point of attention for the interview and a point of departure for the collection of digital data. During the interview, media maps work pretty much like language portraits, in that they capitalize on the affordances of visualization to prompt metalinguistic reflexivity (Busch 2013, 36ff.). The mere process of drawing, Busch argues, creates opportunities to stop, reflect and distance oneself from one's own linguistic (and, in this case, mediational) practices. Visual representation is a mode of meaning-making in itself, in that visual resources such as e.g. layout and colour can all be meaningfully deployed in indexing the value of a particular resource relative to other resources. The visual figure becomes an anchor and reference point for the rest of the narrative interview. It elicits and organises the narrative, for example by enabling the participant to take up shapes and colours as an occasion for sharing language-biographical and techno-biographical details (Barton and Lee 2013). In practical terms, media maps and mediagrams provide a visual and deictic 
point of reference that may help anchor participants' attention and keep them focussed on the topic of discussion. This is consonant with research with participant-generated sociograms (Hogan et al. 2007; Tubaro et al. 2014) which points out the advantages of including a visual depiction of an informant's social network into the data gathering process. In our experience, this proves particularly useful when the interview takes place in the family home amidst constant interruptions such as ringing doorbells and children asking for help. Mediagrams also provide an anchoring point that might help other family members to join the discussion.

Excerpts of digital data can be collected on the spot to contribute to the first version of a mediagram. The researcher requests samples of the informant's mediated interaction with interlocutors who are represented on the drawing, and asks the informant to clarify with that interlocutor whether the data may be used for research purposes. The informants themselves define boundaries of 'shareability' by deciding which parts of which interaction threads to disclose and how to share them, e.g. by means of a download, screenshot or photo. The participants thus actively take part in the collection of interactional data as they choose the interaction to be shared and take decisions about the materiality of the data that is made available. The data each participant makes available is arranged and coded in a calculation sheet, which the source for the compilation of a mediagram. For example, the mediagram participant F2 (figure 6) is based on information collected in the interview and a number of WhatsApp threads he shared with us.

Figure 6 Mediagram of the father in family $2(\mathrm{~F} 2)$ 


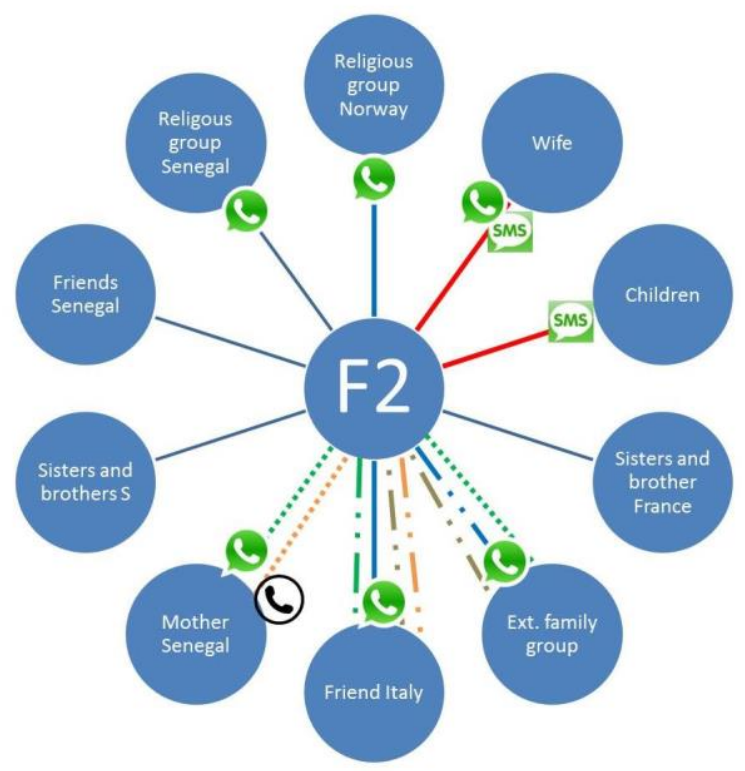

Besides his wife and children in Norway, Father 2 communicates with his mother in Senegal, his sisters and brothers in Senegal, friends in Senegal and Italy. He is member of two religious group-chats, one Norway-based and one Senegal-based, and he also participates in a family-chat with cousins and less close relatives. His preferred media are WhatsApp, SMS, and phone calls. He does not have a Facebook account. With his mother he speaks Fula and Wolof on the phone and via WhatsApp, while his interaction with the extended family group and his friend in Italy is multilingual, drawing on up to four languages.

At this stage, the mediagram for F2 is unfinished. All interlocutors he mentioned during the map-drawing task are included, but his own language and media choices are incomplete. During the interview, F2 provided excerpts of his mediated interaction with his mother (WhatsApp voice messages and phone calls in Fula and Wolof), his nuclear family (Norwegian in SMS and WhatsApp), his friend in Italy (written and spoken WhatsApp messages in different languages), and a WhatsApp group of his extended family (spoken Wolof, spoken and written French and Arabic). However, there is no data on his language and media choices towards friends and siblings in Senegal and 
France and in two religious WhatsApp groups he is part of. These missing bits are identified while compiling the mediagram and discussed at the next meeting.

Missing bits and contradictions that may come up during the compilation of a participant's mediagram are pinpointed to be discussed at the follow-up meeting, where the mediagram is presented to the participant who is then invited to reflect and comment on it (see also Nemcová 2016). The participant is also invited to comment on excerpts of digital interaction that were selected during the compilation process (see Androutsopoulos 2008). The new information obtained in the follow-up interview is then integrated into the calculation sheet, and the mediagram is modified accordingly.

This procedure can be repeated if the time available for fieldwork allows for it, potentially leading to iterative additions to the data collection and improvements of the respective mediagram. This way, on-going changes in the mediational practices of a participant can be captured. Figure 7 summarizes the collaborative process of mediagram compilation and use in six steps.

Figure 7 The mediagram research process step by step

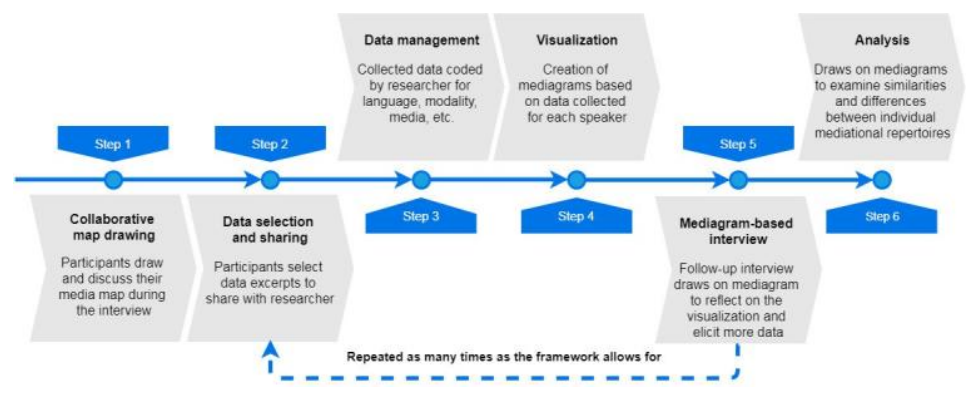

At Step 1, participants draw maps in the interview setting and comment on them. At Step 2, textual data is collected. At Step 3, the data for each participant is organized in a calculation sheet with codes for language, modality, media channel, etc. This calculation sheet serves as basis for compiling the mediagram (Step 4), thereby taking note of uncertainties and/or interesting interactions that the researcher would like to explore further. The mediagram is then presented to the participant at the next data 
collection session (Step 5), where questions are discussed and new digital data that exemplify specific relationships represented in the graph are collected. This new data is used to modify the mediagram, which can be taken back to the participant again at the next meeting, and so on. This cycle of data collection, visualization, ratification, and optimization can in principle be repeated as many times as the fieldwork limits allow for or the participants are eager to collaborate. At the end of the cycle (Step 6) a mediagram can be used for analysis.

\section{Using mediagrams in data elicitation and analysis}

Once re-inserted in a new interview situation (i.e. Step 5), a mediagram is jointly examined by the participant and the researcher in order to be ratified, corrected, or complemented. We illustrate this with an example from the second meeting with family 1, where the first author presents the mediagrams she compiled for each family member. In excerpt 1, the researcher $(\mathrm{K})$ presents the oldest son in the family (S1.1) the first version of his mediagram (see Figure 8 below) and asks for more information about his interaction with his maternal uncle, a new interlocutor that S1.1 has introduced during the interview. S1.1 talks about their media and language choices, then explains that his father often mediates his interaction with the uncle.

Excerpt 1: Discussing the mediagram of Son 1.1

$\mathrm{K} \quad H v o r d a n$ snakker du med han, da?

'How do you talk with him then?'

S1.1 Det er wolof

'It's Wolof'

$\mathrm{K} \quad$ Det er wolof, og da snakker du, eller skriver du, eller?

'It's Wolof, and then you talk or do you write?'

S1.1 Da er det ofte Skype, ja

'Then it's often Skype, yes'

K Skype? Ja 


\author{
'Skype? Yes' \\ S1.1 Ja, det er pappa som dem snakker, så kanskje e kjem inn, si hei og snakke \\ med dem, så \\ 'It's dad who talks and then I may come in, to say hi and talk to them, so'
}

The first version of S1.1's mediagram is based on the media map he drew at our first meeting (see figure 4) and on SMS messages he shared with us. After the second meeting his mediagram was extended to include additional relatives from Senegal and more smartphone apps (figure 9). These additions were based both on the interview and but excerpts of digital interaction that S.1.1 shared with us, which show how he and his cousin in Senegal switch back and forth between writing English and speaking Wolof (in voice messages) in the course of a single WhatsApp exchange. In other cases, such data can confirm information obtained in the interview, e.g. regarding the exclusive use of Norwegian in text messages between S1.1 and his parents. Excerpts from digital interaction can thus lead to changes in the display of language, modality or media choices in a mediagram.

Figure 8 Mediagram of the oldest son in family 1 (S1.1) compiled after first meeting

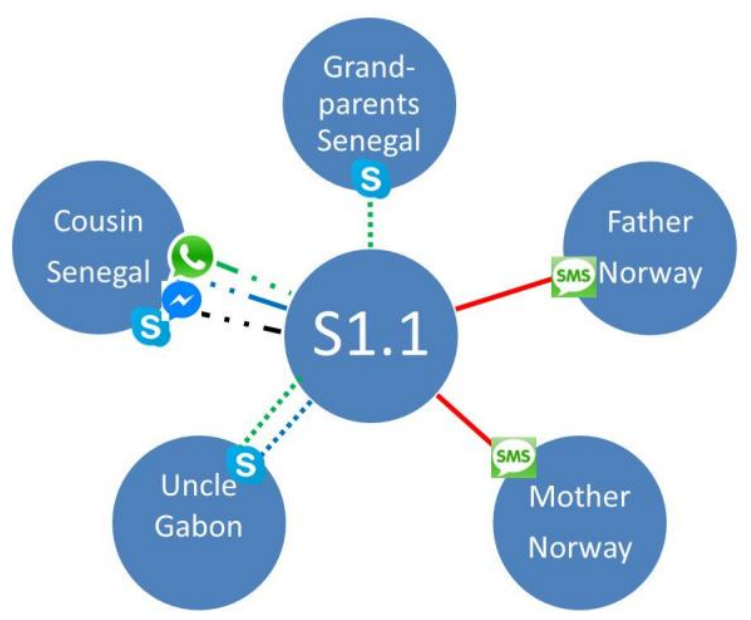

Figure 9 Mediagram of the oldest son in family 1 (S1.1) compiled after second meeting 


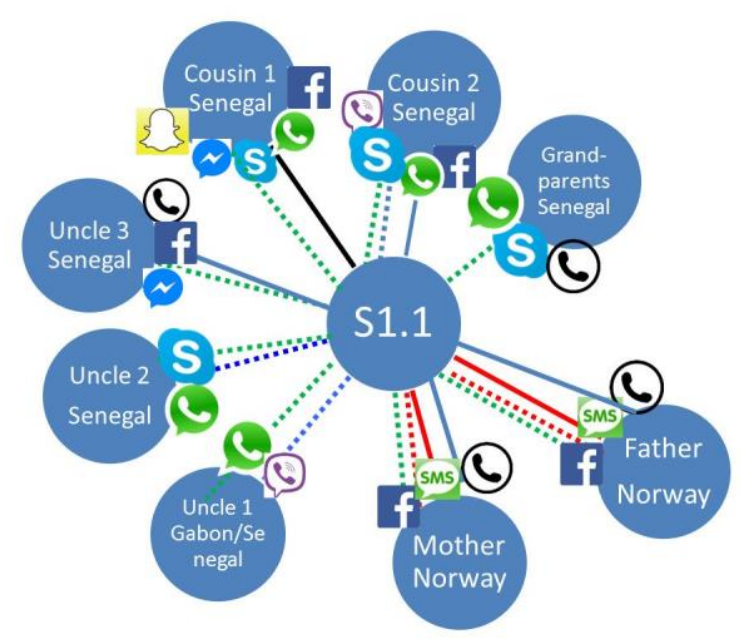

Working together with a participant to identify missing data and possible oversights by the researcher feels much smoother when reference is made to a visual depiction of their social network. Mediagrams can also be used to discuss frequency of interpersonal contact and elicit details on the selection of languages and media applications. If a graph shows two or more media channels for the same interlocutor (e.g. WhatsApp and Facebook messenger), the researcher can query in the follow-up meeting whether both channels are used in equal frequency or their distribution has changed over time. For example, the daughter of family 3 (D3) explained in the followup meeting how she arranges her social network into groups by the choice of media channel. She uses Facebook messenger with what she calls "the children of the adults in the family", whereas WhatsApp is her channel of choice for her closest relatives. With friends from school in Norway, she prefers Snapchat. This participant articulates her repertoire of mediational tools with her social contacts, and in this process certain choices from the linguistic repertoire can become associated with certain apps, e.g. only Norwegian for Snapchat, but English and Wolof in WhatsApp.

Once compiled, mediagrams enable the comparative analysis of mediational repertoires. We exemplify this with a comparison of the fathers in families 1 and 3 (F1 and F3). The mediagram for F1 (figure 10) shows he prefers to write in French and talk 
in Wolof with his brothers in Senegal. However, F1's exchanges with his female cousin in Senegal (lower left part) and his sister who lives in Canada (bottom, middle) also include some written Wolof. A WhatsApp thread and a Facebook messenger conversation that F1 shared with us suggest that he and his cousin often use written Wolof in teasing each other, a finding that echoes patterns on multilingual texting in Senegal (Lexander 2011). Relevant background information here is that F1's cousin is also the wife of one of his brothers, i.e. his sister-in-law. The playful content of these exchanges is in fact consonant with traditional expectations to an in-law and cousin-tocousin relationship (cf. Diop 1985). On the other hand, F1 rarely writes Wolof to his sister, even though she does write Wolof to him. Writing in Wolof is therefore asymmetrical in this pair of interlocutors. This example illustrates the limitations of the visual representation offered by mediagrams and the need to contextualize them in the elicitation process and in analysis. One and the same language and modality choice may correspond to different language styles and genres of communication. The mediagram itself is not designed to indicate such degree of detail.

Figure 10 Mediagram of the father in family 1 (F1)

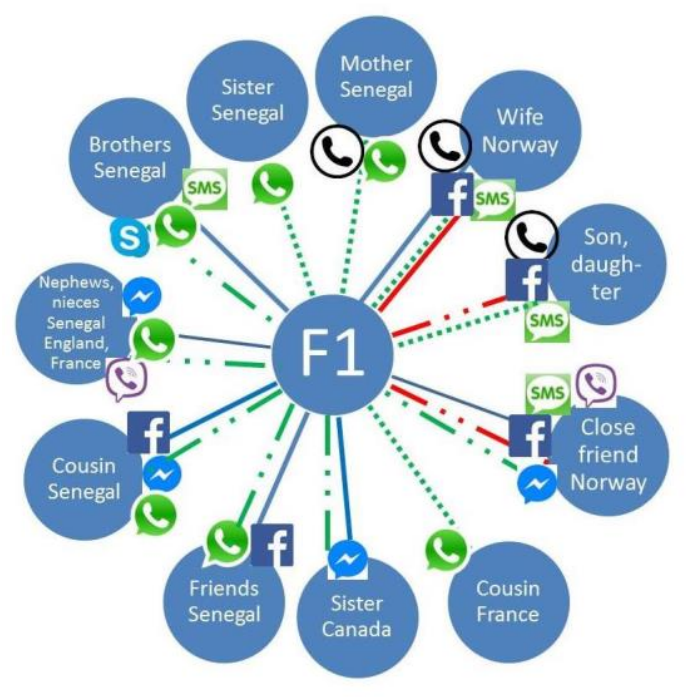


The mediagram of the father in family 3 (Figure 11) displays quite diverse language choices towards different interlocutors. With his mother and his siblings, F3 communicates only in spoken Joola. With his daughter he uses a number of languages when they speak, but only Norwegian when they write to each other. His communication with the daughter's mother who lives in Senegal is also multilingual, but only written. F3 has various business projects in Senegal, which he coordinates from Norway. He writes business email messages in French, while his business phone calls come in Joola. This distribution of languages to modalities reflects the diglossic structure of Senegal, where literacy is traditionally tied to the ex-colonial language, French (Lexander 2011). With his Senegalese friend in Norway, F3 uses Norwegian alongside two Senegalese languages, Wolof and Joola, in speaking and writing. The comparison suggests that $\mathrm{F} 3$ is willing and able to draw on these different languages in his distant digital communication with this family, friends and project partners, thereby making contextually meaningful choices (e.g. for business emails as opposed to family phone calls). F3 is a vivid example for the kaleidoscopic structure of languages, modalities and media channels, which are co-selected according to interlocutor and communicative purpose. His language choices differ from those of $\mathrm{F} 1$, and this is in part due to the fact that coming from the south of Senegal, F3 has more languages in his repertoire than F1, who comes from a Wolof-speaking family and a Wolof-dominant city.

Figure 11 Mediagram of the father in family 3 (F3) 


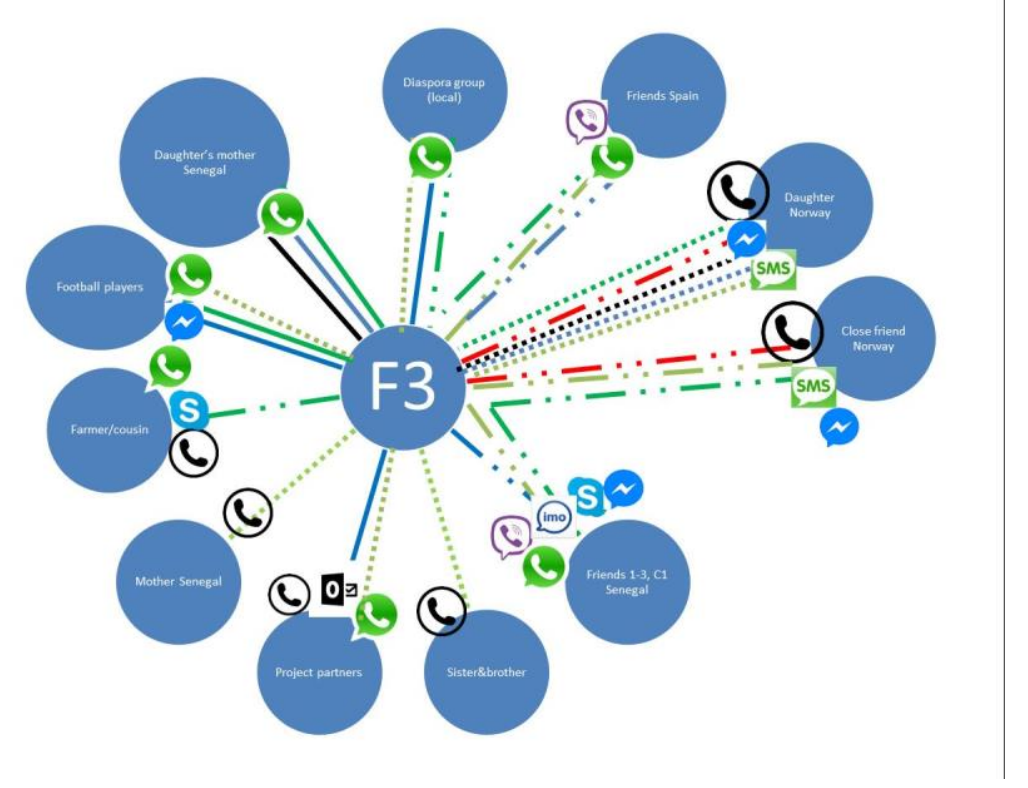

It is important to emphasize that mediagrams do not work in isolation, but together with the contextual information collected in fieldwork. Mediagrams themselves cannot reveal the different factors that shape speakers' mediational choices. These must be disclosed in individual and family interviews around the graphs. For example, the graph for D3 (see Figure 4 above) indicates the use of spoken Joola on the phone for communication with her grandmother, but details on this are only disclosed in a joint interview with father and daughter in family 3 (F3 and D3), where D3 reports that her grandmother from Senegal presses her to use spoken Joola by refusing to reply when D3 talks to her in Wolof on the phone. Moreover, each version of a mediagram provides insight into a person's mediational repertoire at a specific point in time, and a sequence of mediagram versions may therefore reveal changes in a mediational repertoire. To provide an example, the mother in family 1 (M1) complained at our first two meetings that her sisters in Senegal did not use the Internet, making distant interaction quite difficult. A regular phone call was the only available mode, for which the sisters depended on phone cards, and conflicts could arise in case the phone card credit was insufficient. At the time of our third meeting, both of M1's sisters had started using 
WhatsApp, thus making communication more frequent and less dependent on financial limitations. The sisters could now send voice messages and videos, e.g. from a flood in their neighbourhood. Communication had become not only less expensive, but also more multimodal.

\section{Discussion and conclusions}

A mediagram is a method for eliciting and visualizing the co-patterning of language, modality and media choices in an individual's mediated communicative practices. This paper discusses how mediagrams can be compiled and used in data elicitation and analysis together with interview transcripts and textual data. Being part of a digital ethnography approach, mediagrams are not conceived of as a stand-alone tool. They represent both an outcome of information elicited in interviews (and digital data) and an input into a subsequent exchange between participant and researcher, which may result in a mediagram being verified, modified, or contextualized through stories and digital interaction excerpts shared by the informant.

As a visual representation, mediagrams have a dual function. First, they may help the analyst identify at a glance similarities and differences across individual mediational practices. In this regard, their advantage over the textual and numerical data on which they rely is not accuracy, but conciseness and practicality. Second, mediagrams are a resource that facilitates the data-collection process itself by providing an anchor of joint attention for collaborative reflexion. We also suggest that mediagrams offer various opportunities for comparative analysis with regard to the mediational repertoires of individuals, families and generations, their changes in time, the social meaning of particular media choices (cf. Madianou and Miller 2012), implications for heritage languages, and so on. The mediagrams presented here are 
compiled manually, and opportunities for automated computerized compilation remain to be explored.

The method outlined in this paper is consonant with principles and aims of citizen science, i.e. "the engagement of non-professionals in conducting scientific research in collaboration with professional scientists or research institutions" (Rymes and Leone 2014; Svendsen 2018, 138). As part of citizen science, citizen sociolinguistics "includes non-professionals in doing sociolinguistic research, in collecting data, in registering them, analysing and interpreting them" (Svendsen 2018, 141, author's emphasis). As our discussion suggests, mediagrams constitute both a visualisation of (preliminary) findings and a communication of these findings to informants. In the course of the research, the participants have a say in selecting information they disclose to us (Step 1), in the compilation of digital data (Step 2), and in the feedback they offer on the first version of their mediagram (Step 5). The mediagram method is also consonant with citizen sociolinguistics in its potential to increase sociolinguistic awareness. This became evident with some of our participants when the difference between what speakers say they do (based on subjective reports in interviews) and what they actually do (based on collected digital data) became a topic of reflection for the participants themselves during our meeting. Not least, mediagrams represent an accessible research outcome. For example, when D4.1 first saw her mediagram she asked if she could take a photo of it. This is a material result of what she contributed to the study, which she can readily understand and use as she likes. This way, participants may develop a feeling of ownership to the project.

From a critical angle, we point out that the present version of mediagrams features representational shortcomings, notably related to frequency of contact and the directionality of language and modality choices, which could potentially be amended in 
later versions. Unlike the network graphs by Nemcová (2016), mediagrams do not represent frequency of contact between two interlocutors. Even though frequency of contact is discussed in the interviews and can to a certain extent be read off the digital data participants share with us, we found it difficult to measure consistently, especially due to its instability over time. For example, the oldest son in family 1 (S1.1) had daily contact with his cousins in Senegal for a long period, which slowed down as S1.1 became occupied by other activities in Norway. In the transnational communication processes discussed here, close and regular contact may take place for a certain period and then slow down or stop altogether for a variety of reasons. It was therefore decided to deal with such variation in qualitative analysis rather than the visualization. Regarding directionality, a mediagram represents the language modalities selected for interaction with a certain interlocutor, but does not distinguish the directionality of modality choice between interlocutors. This becomes an issue when the choice of language modality is asymmetrical. For example, the youngest daughter in family 4 (D4.2) is not comfortable with speaking Wolof and prefers to write it, even when she receives voice messages in Wolof by a relative. Her mediagram indicates that her communication with that relative is both spoken and written in Wolof, but does not indicate that D4.2 produces all written Wolof in this exchange, while all spoken Wolof comes from her relative. This difference could be added on to the graph, though on the cost of added graphic complexity.

A final point to be raised concerns the theoretical understanding of language(s) implicated in mediagrams. At first sight, the color-coding in the graph seems to reinforce an understanding of languages as bound and homogenous entities that can be categorically separated from each other, i.e. an understanding sharply criticized in recent discussions of translanguaging and metrolingual practices (García and Li 2014; 
Pennycook and Otsuji 2016). We consider this graphic separation a sort of 'necessary evil', which neither reflects the metalinguistic awareness of some of our participants nor our own theoretical and methodological positioning. It is a representational shortcoming that mediagrams share with other similar visual representations, including the network graphs and language portraits reviewed above. Our position here is that mediagrams have limits in what they can visually represent. Subtle translanguaging practices are not part of their visual potential, which is precisely why they depend on qualitative analysis to be adequately contextualized. For example, the mediagram for participant F2 (Figure 6) indicates his communication with his mother in Senegal is in spoken Wolof and Fula. However, qualitative analysis of their WhatsApp voice-messages shows that the mother frequently introduces her Fula voice-messages with the French opening Allô ('Hello'). This could be added to the graph simply by adding a dotted blue line for 'spoken French', though with the effect of making this linguistic choice appear as important as spoken Fula, which is just not accurate for F2 and his mother. In the present version, introducing gradations of this kind would blow up the graphic complexity of mediagrams to the expense of their readability. Similar issues come up when trying to decide which language certain words, or indeed entire interactions, ought to be assigned to. When we asked the members of Family 3 what languages they use together, D3 said alle ('all'), and her father said, vi tar litt av hvert ('we take a little here and a little there'). F3 also explained he had never thought of his language practices as made up of different languages until he participated in this project. We consider it more productive to contextualize mediagrams in qualitative analysis in order to bring to the fore the fluidity and subtlety of the linguistic and mediational choices they represent. On the other hand, as Pennycook and Otsuji $(2016,274)$ remind us, there is not only fluidity, but also fixity in language. As our examples in this paper illustrate, people draw on 
language labels to discuss their language practices. We therefore suggest it is possible for researchers to use language-labels with participants and nonetheless signal they do not think of languages as bound entities. Contextualizing mediagrams in qualitative analysis counterbalances the impression of separating languages and brings to the fore a more fluid understanding of language and media practices.

\section{References}

Androutsopoulos, Jannis. 2008. "Discourse-Centred Online Ethnography.” Language@Internet 5 (08). URL: http://www.languageatinternet.de. Androutsopoulos, Jannis. 2014. "Moments of Sharing: Entextualization and Linguistic Repertoires in Social Networking." Journal of Pragmatics 73: 4-18.

Androutsopoulos, Jannis. 2015. "Networked Multilingualism. Some Practices on Facebook.” International Journal of Bilingualism 19 (2): 185-205. Androutsopoulos, Jannis and Kasper Juffermans. 2014. "Digital Language Practices in Superdiversity. Introduction." Discourse, Context and Media 4-5: 1-6. Androutsopoulos, Jannis and Andreas Stæhr. 2018. "Moving Methods Online. Researching Digital Language Practices." In The Routledge Handbook of Language and Superdiversity edited by Angela Creese and Adrian Blackledge, 118-132. London: Routledge.

Barton, David and Carmen Lee. 2013. Language Online. Investigating Digital Texts and Practices. London: Routledge.

Blackledge, Adrian and Angela Creese. 2017. "Translanguaging in Mobility". In The Routledge Handbook of Migration and Language edited by Suresh Canagarajah, 31-46. London: Routledge.

Blommaert, Jan and Ad Backus. 2013 “Superdiverse Repertoires and the Individual.” In Multilingualism and Multimodality. Current Challenges for Educational Studies edited by Ingrid de Saint-Georges and Jean-Jacques Weber, 11-32. Rotterdam: Sense.

Blommaert, Jan and Ben Rampton. 2011. "Language and Superdiversity.” Diversities $13(2): 1-21$. 
Brandehof, Jelke. 2014. Superdiversity in a Cameroonian Diaspora Community in Ghent: The Social Structure of Superdiverse Networks. MA dissertation, Tilburg University. URL: http://arno.uvt.nl/show.cgi?fid=136106

Bucher, Taina and Helmond, Anne. 2017. "The Affordances of Social Media Platforms". In The SAGE Handbook of Social Media edited by Jean Burgess, Thomas Poell and Alice Marwick, 233-253. London/New York: Sage.

Busch, Brigitta. 2012. "Linguistic Repertoire Revisited.” Applied Linguistics 33 (5): 503-523.

Busch, Brigitta. 2013. Mehrsprachigkeit. Wien: Facultas (UTB).

Busch, Brigitta. 2017. "Expanding the Notion of the Linguistic Repertoire: On the Concept of Spracherleben. The Lived Experience of Language." Applied Linguistics 38 (3): 340-358.

Curdt-Christiansen, Xiao Lan and Elizabeth Lanza. 2018. "Language Management in Multilingual Families: Efforts, Measures and Challenges." Multilingua 37 (2): $123-130$.

Diop, Abdoulaye-Bara. 1985. La famille wolof. Tradition et changement. Paris: Karthala.

Drahota, Amy and Ann Dewey. 2008. "The Sociogram. A Useful Tool in the Analysis of Focus Groups.” Nursing Research 57 (4): 293-297.

Fogle, Lyn W. and Kendall A. King. 2013. "Child Agency and Policy in Transnational Families." Issues in Applied Linguistics 19 (1): 1-25.

Garcìa, Ofelia and Li Wei. 2014. Translanguaging: Language, Bilingualism and Education. Basingstoke, UK: Palgrave Macmillan.

He, Agnes W. 2012. "Heritage Language Socialization”. In The Handbook of Language Socialization edited by Alessandro Duranti, Elinor Ochs and Bambi Schiefflin, 587-609. Malden MA, Wiley-Blackwell.

Hogan, Bernie, Juan-Antonio Carrasco and Barry Wellman. 2007. Visualizing Personal Networks: Working with Participant-aided Sociograms. Field Methods 19 (2): 116-144.

Huang, Weidong, Seok-Hee Hong and Peter Eades. 2006. "How People Read Sociograms: A Questionnaire Study." Proc. Asia Pacific Symposium on Information Visualisation (APVIS2006): 199-206. 
King, Kendall and Elizabeth Lanza. 2017. "Ideology, Agency and Imagination in Multilingual Families: An Introduction.” International Journal of Bilingualism, 1-7. Advance online publication. doi:10.1177/1367006916684907

Lanza, Elizabeth and Kristin Vold Lexander. Forthc. "Family Language Practices in Multilingual Transcultural Families”. In Transdisciplinary Perspectives on Multilingualism edited by Simona Montanari and Suzanne Quay. Berlin \& New York: de Gruyter.

Lee, Carmen. 2009. “Learning 'New’ Text-making Practices Online: From Instant Messaging to Facebooking." The International Journal of Learning 16 (12): 111-124. DOI: 10.18848/1447-9494/CGP/v16i12/46757

Lee, Carmen. 2017. Multilingualism Online. Abingdon/New York: Routledge.

Lee, Jin Sook. 2006. "Exploring the Relationship between Electronic Literacy and HL Maintenance." Language Learning and Technology 10 (2): 93-113.

Lexander, Kristin V. 2011. "Texting and African Languages Literacy." New Media and Society 13 (3): 427-443.

Madianou, Mirca 2014 "Polymedia Communication and Mediatized Migration: An Ethnographic Approach.” In Mediatization of Communication edited by Knut Lundby, 323-348. Berlin: De Gruyter.

Madianou, Mirca and Daniel Miller. 2012. Migration and New Media: Transnational Families and Polymedia. London: Routledge.

Milroy, Lesley. 1980. Language and Social Networks. Oxford: Basil Blackwell Nemcová, Monika. 2016. "Rethinking Integration: Superdiversity in the Networks of Transnational Individuals.” Tilburg Papers in Culture Studies, paper 167.

URL:https://www.tilburguniversity.edu/upload/d1833428-a654-4a72aefce19edeea82d_TPCS_167_Nemcova.pdf

Paolillo, John C. 1999. “The Virtual Speech Community: Social Network and Language Variation on IRC.” Journal of Computer-Mediated Communication 4 (4): 0-0. URL:https://doi.org/10.1111/j.1083-6101.1999.tb00109.x

Pennycook, Alistair and Emi Otsuji. 2016. "Lingoing, Language Labels and Metrolingual Practices.” Applied Linguistics Review 7(3): 259-277.

Purkarthofer, Judith. 2017. "Building Expectations: Imagining Family Languages Policy and Heteroglossic Social Spaces.” International Journal of Bilingualism. Advance online publication. doi:10.1177/1367006916684921 
Reershemius, Gertrud. 2017. "Autochthonous Heritage Languages and Social Media: Writing and Bilingual Practices in Low German On Facebook." Journal of Multilingual and Multicultural Development 38 (1): 35-49. doi:10.1080/01434632.2016.1151434

Rymes, Betsy and Andrea R. Leone. 2014. "Citizen Sociolinguistics: A New Media Methodology for Understanding Language and Social Life." Working Papers in Educational Linguistics 29: 25-43.

Scollon, Ron. 2001. Mediated Discourse: The Nexus of Practice. London: Routledge.

Sharma, Devyani. 2017. "Scalar Effects of Social Networks on Language Variation." Language Variation and Change, 29 (3): 393-418.

Svendsen, Bente A. 2018. “The Dynamics of Citizen Sociolinguistics.” Journal of Sociolinguistics 22 (2): 137-160.

Tubaro, Paola, Antonio A. Casilli and Lise Mounier. 2014. "Eliciting Personal Network Data in Web Surveys through Participant-generated Sociograms." Field Methods 26 (2) 107-125.

Wilson, Sonja. 2019. Family language policy through the eyes of bilingual children: the case of French heritage speakers in the UK, Journal of Multilingual and Multicultural Development. Advance online publication. DOI: 10.1080/01434632.2019.1595633

Zhu Hua and Li Wei. 2016. Transnational Experience, Aspiration and Family Language Policy. Journal of Multilingual and Multicultural Development 37 (7): 655666. doi: 10.1080/01434632.2015.1127928

This work was partly supported by the Research Council of Norway through its Centres of Excellence funding scheme, project number 223265. Our thanks go to Natacha Céline Buntinx for her support with graphic design. 
${ }^{\mathrm{i}}$ A red frame signifies communication with an interlocutor (or a group) takes place at least once a week, a purple frame indicates less frequent contact, and a yellow frame indicates communication no longer takes place.

${ }^{\text {ii }}$ All ages at the start of fieldwork in 2017.

iii Language modality is often implicitly inferred from media choices, but not always so. Indeed, WhatsApp and Skype enable both speaking and writing. 